\title{
ANALISIS PENDAPATAN DAN TINGKAT KESEJAHTERAAN RUMAH TANGGA PETANI TEBU TANAM DAN KEPRASAN DI KABUPATEN BANTUL
}

\section{Analisys of Income and Walfare of Planting Cane and Ratoon Cane Farm Household in Bantul District}

\author{
Wasilatur Rohmah $^{1)}$, Any Suryantini ${ }^{2)}$, Slamet Hartono ${ }^{2)}$ \\ ${ }^{1)}$ Jurusan Sosial Ekonomi Pertanian, Fakultas Pertanian, Universitas Gadjah Mada \\ ${ }^{2)}$ Fakultas Pertanian, Universitas Gadjah Mada
}

\begin{abstract}
This study aimeds to determine (1) factors affecting sugarcane production (2) factors affecting the sugarcane income (3) the risk of sugarcane production and income (4) contribution of sugarcane farm-income to farmer households' income (5) income distribution among farmer households (6) the level of farmer households' welfare in Bantul District. The basic method of this research was descriptive analytical, sample was chosen purposively. Number of respondent was 30 sugarcane farmers. Analytical tools were the Cobb-Douglas production function and Unit Output Price (UOP) profit function. The result showed that (1) factors that positively influencing to the sugarcane production were land acreage, sugarcane seedlings, ZA fertilizer, pesticides, cultivating labor, harvesting labor and cropping method (2) factor that positively influencing to the sugarcane income was land acreage. Income factor that had negatively influence to the sugarcane income were sugarcane seedling's price and cultivating labor's wage (3) production risk of second ratoon sugarcane was the highest among other sugarcane planting systems. Income risk of second ratoon sugarcane was the highest among other sugarcane planting system (4) contribution of sugarcane income to the farm household income was the majority (5) sugarcane income could improve farm household's income distribution (6) sugarcane farm-households was classified as a prosperous household.
\end{abstract}

Keyword: production, income, sugarcane, risk.

\section{INTISARI}

Penelitian bertujuan untuk (1) Mengetahui produksi usahatani tebu dan faktor-faktor yang mempengaruhinya. (2) Mengetahui pendapatan usahatani tebu dan faktor-faktor yang mempengaruhinya. (3) Mengetahui risiko produksi dan risiko pendapatan usahatani tebu. (4) Mengetahui kontribusi pendapatan usahatani tebu terhadap pendapatan total rumah tangga petani. (5) Mengetahui distribusi pendapatan rumah tangga petani tebu di Kabupaten Bantul. (6) Mengetahui tingkat kesejahteraan rumah tangga petani tebu di Kabupaten Bantul. Metode dasar yang digunakan dalam penelitian ini metode deskriptif analisis. Penentuan sampel lokasi dan sampel petanidengan metode purposive random sampling; sejumlah 30 petani tebu. Metode analisis menggunakan fungsi produksi Cobb-Douglas dan fungsi keuntungan Cobb-Douglas dengan teknik Unit Output Price (UOP). Hasil penelitian menunjukkan (1) Faktor-faktor produksi tebu yang berpengaruh positif terhadap produksi usahatani tebu adalah luas lahan, bibit, pupuk ZA, pestisida, tenaga kerja garap, tenaga kerja panen dan sistem penanaman. (2) Faktor-faktor pendapatan tebu yang berpengaruh positif terhadap pendapatan usahatani tebu adalah luas lahan sedangkan yang berpengaruh negarif adalah harga bibit dan upah tenaga kerja garap. (3) Tebu keprasan kedua memiliki risiko produksi dan risiko pendapatan paling tinggi. (4) Pendapatan usahatani tebu memiliki kontribusi yang tinggi terhadap pendapatan total rumah tangga. (5) Pendapatan usahatani tebu dapat memperbaiki ketimpangan distribusi pendapatan rumah tangga petani. (6) Rumah tangga petani tebu di Kabupaten Bantul tergolong rumah tangga yang sejahtera.

Kata kunci: produksi, pendapatan, tebu, risiko, kesejahteraan

\section{PENDAHULUAN}

Permasalahan industri gula nasional sudah berlangsung sejak tahun 1970 yang mencakup aspek produksi yang berkaitan dengan usahatani tebu, konsumsi, efisiensi pabrik gula, tataniaga dan perdagangan internasional. Permasalahan aspek produksi berkaitan dengan menurunnya kemampuan menghasilkan gula untuk memenuhi kebutuhan gula dalam negeri (Prabowo, 1998).
Turunnya produksi dan produktivitas gula disebabkan berbagai faktor seperti: budidaya tebu di bawah standar, penanaman dibawah masa optimal, mayoritas lahan tebu adalah lahan kering dengan produktivitas lebih rendah dari lahan sawah, proporsi tanaman keprasan lebih besar, mutu bibit tidak optimal, sistem tebang angkut yang tidak optimal dan adanya gangguan hubungan antara pabrik gula dan petani (Muslim, 
2003:283: Siagian, 2004:56). Departemen pertanian sejak pertengahan tahun 2003 telah mengambil inisiatif untuk merancang pembangunan Industri Gula Nasional (IGN) secara komprehensif yang mampu mendorong peningkatan produksi gula nasional secara efisien, mengurangi impor gula dan meningkatkan pendapatan produksi petani tebu. Kebijakan itu mencakup pemecahan berbagai masalah budidaya tebu, kemitraan antara pabrik gula dengan petani tebu, efisiensi pabrik gula, perdagangan dan impor serta dukungan pemerintah terutama infrastruktur di lahan kering, penguatan Research and Development dan dukungan harga yang menguntungkan petani (P3GI, 2003; LP IPB, 2002; Booker Tate Ltd, 1999).

Gula merupakan salah satu komoditas strategis dalam perekonomian Indonesia. Dengan luas areal sekitar 350 ribu ha pada periode 20002005, industri gula berbasis tebu merupakan salah satu sumber pendapatan bagi sekitar 900 ribu petani dengan jumlah tenaga kerja yang terlibat mencapai sekitar 1,3 juta orang. Gula juga merupakan salah satu kebutuhan pokok masyarakat dan sumber kalori yang relatif murah. Karena merupakan kebutuhan pokok, maka dinamika harga gula akan mempunyai pengaruh langsung terhadap laju inflasi. Dengan posisinya yang penting dan sejalan dengan revitalisasi sektor pertanian, maka industri gula berbasis tebu juga perlu melakukan berbagai upaya sehingga sejalan dengan revitalisasi sektor pertanian. Hal ini menuntut industri gula berbasis tebu perlu melakukan berbagai perubahan dan penyesuaian guna meningkatkan produktivitas, dan efisiensi, sehingga menjadi industri yang kompetitif, mempunyai nilai tambah yang tinggi, dan memberi tingkat kesejahteraan yang memadai pada para pelakunya, khususnya petani (Departemen Pertanian, 2007).

Secara lebih rinci tujuan dari penelitian ini adalah:

1. Mengetahui produksi tebu dan faktor-faktor yang mempengaruhinya.

2. Mengetahui pendapatan petani tebu dan faktor-faktor yang mempengaruhinya.

3. Mengetahui risiko produksi dan risiko pendapatan tebu.
4. Mengetahui kontribusi pendapatan tebu terhadap pendapatn total rumah tangga tani.

5. Mengetahui distribusi pendapatan petani tebu di Kabupaten Bantul.

6. Mengetahui tingkat kesejahteraan petani tebu di Kabupaten Bantul.

\section{TINJAUAN PUSTAKA}

\section{Teori Produksi}

Konsep dasar ilmu ekonomi adalah fungsi produksi. Konsep ini merupakan cara sistematis yang menunjukkan hubungan antara berbagai jumlah sumber daya atau input yang dapat digunakan untuk menghasilkan produk. Hubungan yang sama dalam disiplin ilmu pertanian lainnya dikenal sebagai response curve, yield curve, atau input/output relationships. Apapun namanya, suatu fungsi produksi menunjukkan jumlah output yang dihasilkan melalui penggunaan input variabel dalam jumlah yang berbeda-beda. Secara matematis fungsi produksi didefinisikan sebagai berikut (Haryanto et al, 2009):

$$
\mathrm{Q}=\mathrm{f}\left(\mathrm{X}_{1}, \mathrm{X}_{2}, \ldots, \mathrm{X}_{\mathrm{n}}\right)
$$

Q adalah kuantitas produk tertentu, sedangkan $\mathrm{X}_{1}, \quad \mathrm{X}_{2}, \quad \ldots, \quad \mathrm{X}_{\mathrm{n}}$ menggambarkan kuantitas sejumlah $\mathrm{n}$ input yang digunakan dalam proses produksi. Persamaan di atas menyatakan bahwa output merupakan fungsi dari tingkat penggunaan input.

Konsep fungsi Cobb Douglas ada suatu persamaan yang melibatkan dua atau lebih variabel, satu variabel independen dan yang lainnya disebut variabel independen. Model matematis umum fungsi produksi Cobb Douglas adalah sebgai berikut ( Soekartawi, 1994):

$$
\mathrm{Q}=\mathrm{AL}^{\alpha} \mathrm{K}^{\beta}
$$

Keterangan:

Q: output produksi

A: intersep (parameter efisiensi)

$\mathrm{K}$ : input 1 (modal)

L: input 2 (tenaga kerja)

$\alpha$ : elastisitas input 1 (modal)

$\beta$ : elastisitas input 2 (tenaga kerja)

Cara memperoleh fungsi produksi Cobb Douglas dapat diperoleh dengan membuat persamaan linier, sehingga menjadi: 


$$
\ln \mathrm{Q}=\ln \mathrm{A}+\alpha \ln \mathrm{K}+\beta \ln \mathrm{L}+\mu,
$$

dengan meregresi persamaan fungsi produksi Cobb Douglas tersebut maka secara mudah akan diperoleh parameter efisiensi (A) dan elastisitas inputnya (Soekartawi, 1994).

\section{Teori Pendapatan}

Usahatani adalah himpunan dari sumbersumber alam yang terdapat di tempat itu yang diperlukan untuk produksi seperti tanah dan air, perbaikan-perbaikan yang telah dilakukan di atas tanah itu, sinar matahari, bangunan-bangunan yang didirikan di atas tanah dan sebagainya (Mubyarto, 1997).

Usahatani akan dianggap berhasil ketika dapat menghasilkan pendapatan yang cukup untuk membayar alat-alat yang digunakan, bunga modal dalam usahatani, membayar upah tenaga kerja dalam keluarga, mengembalikan modal awal dan membayar petani sendiri sebagai manajer dalam kegiatan usahatani (Hadisapoetra, 1973).

Fungsi keuntungan Cobb-Douglas digunakan dalam penelitian ini adalah fungsi keuntungan yang berasal dari fungsi CobbDouglas dengan teknik Unit Output Price (UOP) yang merupakan fungsi yang melibatkan harga produksi dan harga faktor produksi yang telah dinormalkan dalam bentuk double natural logarithm (Soekartawi et al, 2003). Fungsi ini digunakan untuk mengukur pengaruh berbagai perubahan input terhadap output. Teknik ini didasarkan pada asumsi bahwa tujuan petani berproduksi adalah untuk memaksimumkan keuntungan dan bukannya memaksimumkan kepuasan. UOP Cobb-Douglas profit function adalah fungsi yang melibatkan harga produksi. Produksi yang telah dinormalkan dengan harga tertentu, yang mempunyai arti besarnya keuntungan dan variabel lain dibagi dengan besarnya harga produksi.

Yotopoulus dan Nugent menurunkan fungsi keuntungan yang berasal dari fungsi produksi sebagai berikut:

$$
\mathrm{Y}=\mathrm{F}(\mathrm{X} 1, \ldots, \mathrm{Xm} ; \mathrm{S} 1, \ldots, \mathrm{Sn})
$$

Keterangan:

$\mathrm{Y}=$ output

$\mathrm{X}=$ input variable
$\mathrm{S}=$ input tetap

Berdasarkan fungsi keuntungan pada persamaan (1), maka Yotopoulus dan Nugent (1976) merumuskan persamaan fungsi keuntungan sebagai berikut:

$\Pi=p Y\left(X_{1}, \ldots, X_{m} ; S_{1}, . ., S_{n}\right)-\sum_{j=1}^{m} v X 1 \ldots m$

Keterangan :

$\Pi \quad$ : keuntungan

$\mathrm{P} \quad$ : harga output per unit

$\mathrm{Y} \quad$ : otal output

$\mathrm{X} 1, \ldots \mathrm{m}$ : faktor produksi variabel ke-1 hingga ke-m

$\mathrm{S} 1, \ldots . \mathrm{n}$ : faktor produksi tetap ke-1 hingga ke-n

$\mathrm{V}$ : harga input

Untuk mendapatkan keuntungan yang maksimal, syarat yang harus dipenuhi adalah diferensiasi pertama $\pi$ terhadap $\mathrm{x}$ harus sama dengan nol, sehingga:

$\frac{d \pi}{d X}=0$

$p \cdot \frac{d \pi}{d X}-v=0$

$p \cdot \frac{d \pi}{d X}=v$

atau nilai produk marginal dari penggunaan input $x$ sama dengan harga input $x$. Dengan menyatakan $\mathrm{v}^{*}=\mathrm{v} / \mathrm{p}$ sebagai harga input yang dinormalkan, maka persamaan (5) dapat ditulis sebagai:

$\frac{d Y}{d X}=v *$

Dengan menormalkan persamaan (6) maka persamaannya menjadi:

$\pi *=\frac{\pi}{p}=Y(X 1, \ldots, X m ; S 1, \ldots, S n)-\sum_{i=1}^{m} v * X i *$ ..(7)

Dengan menggunakan fungsi Cobb-Douglas, maka fungsi keuntungan yang dinormalkan dalam bentuk double natural logarithm ditulis sebagai berikut:

Ln $\pi^{*} \quad=\quad \ln \mathrm{A}^{*}+$

$\sum_{j=1}^{m} \alpha i * \ln v i *+\sum_{j=1}^{n} \beta i * \ln S i \ldots . .(8)$

Keterangan:

$\Pi^{*} \quad=$ keuntungan yang dinormalkan

$\mathrm{A}^{*} \quad=$ intersept

$\alpha^{*} \mathrm{i} \quad=$ koefisien harga produksi variabel ke-i 
$\beta^{*} \mathrm{i}=$ koefisien faktor produksi tetap

$\mathrm{v}^{*} \quad=$ harga faktor produksi variabel ke-i yang dinormalkan

$\mathrm{Si} \quad=$ kuantitas faktor produksi tetap

Seperti dijelaskan sebelumnya, fungsi keuntungan Cobb-Douglas adalah dipakai untuk mengukur tingkatan efisiensi. Begitu pula halnya dengan UOP-CDPF. Dalam UOP-CDPF ini asumsinya petani atau pengusaha adalah melakukan tindakan yang berorientasikan memaksimumkan keuntungan juga berlaku asumsi lainnya, yaitu (Soekartawi, 1994):

1. Fungsi keuntungan adalah menurun bersamaan dengan bertambahnya jumlah fixed variable (faktor produksi tetap).

2. Masing-masing individu sampel memperlakukan harga input yang bervariasi sedemikian rupa dalam usaha memaksimumkan keuntungan.

3. Walaupun masing-masing individu petani atau pengusaha mempunyai fungsi produksi yang sama tetapi fungsi tersebut menjadi berbeda kalau ada perbedaan penggunaan input tetap yang berbeda jumlahnya.

\section{Distribusi Pendapatan}

Distribusi pendapatan dapat dilihat melalui beberapa indikator yaitu Arsyad (2010):

\section{a. Kurva Lorentz}

Kurva Lorentz menunjukkan hubungan kuantitatif antara persentase penduduk dan persentase pendapatan yang mereka terima, misalnya dalam satu tahun. Jumlah penerima pendapatan digambarkan pada sumbu horizontal, tidak dalam angka mutlak namun dalam persentase kumulatif. Pada ujung horizontal menunjukkan jumlah 100 persen penduduk yang dihitung pendapatannya. Sumbu vertikal menunjukkan pangsa pendapatan yang diterima oleh masing-masing persentase jumlah penduduk. Jumlah ini juga kumulatif sampai 100 persen, dengan demikian kedua sumbu ini sama panjangnya dan akhirnya membentuk bujur sangkar. Sebuah garis diagonal kemudian digambarkan melalui titik origin menuju sudut kanan atas dari bujur sangkar tersebut. Setiap titik pada garis diagonal tersebut menunjukkan bahwa persentase pendapatan yang diterima sama persis dengan persentase penerima pendapatan tersebut.

Semakin jauh Kurva Lorenz tersebut dari garis diagonal (kemerataan sempurna), maka semakin tinggi pula derajat ketidakmerataan yang ditunjukkan. Keadaan yang paling ekstrim dari ketidakmerataan sempurna, misalnya keadaan dimana seluruh pendapatan hanya diterima oleh satu orang, akan ditunjukkan oleh berhimpitnya Kurva Lorenz tersebut dengan sumbu horizontal bagian bawah dan sumbu vertikal sebelah kanan.

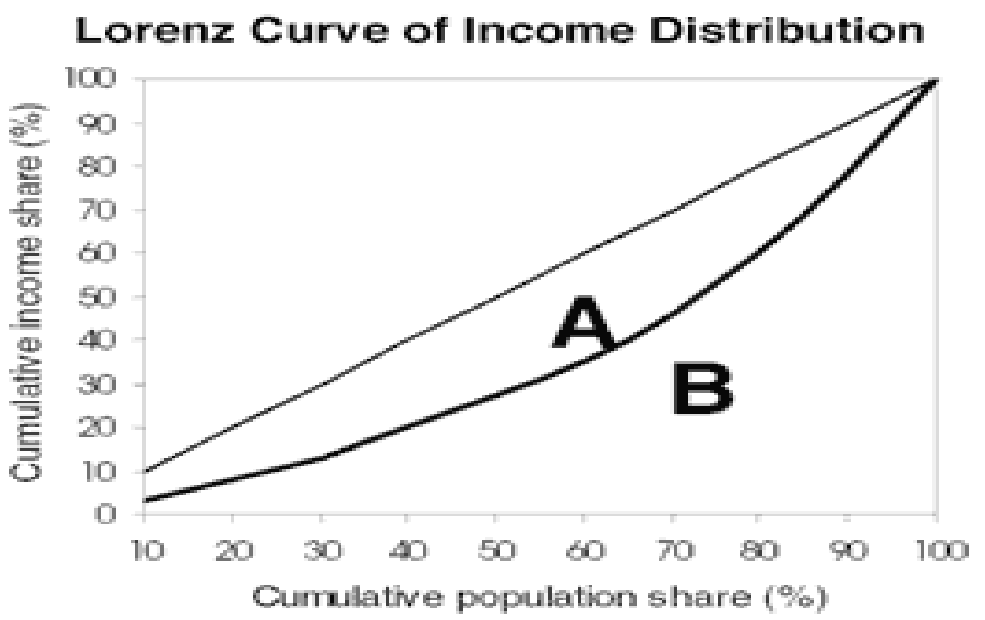

Gambar 2.1. Kurva Lorenz (Arsyad, 2010) 
Semakin tinggi derajat ketidak merataannya, maka Kurva lorenz tersebut juga akan semakin melengkung (cembung) dan semakin mendekati sumbu horizontal sebelah bawah. Hal ini karena tidak ada suatu negarapun yang mengalami kemerataan sempurna ataupun ketidakmerataan sempurna, maka kurvakurva Lorenz setiap negara akan terletak di sebelah kanan kurva diagonal (Arsyad, 2010).

\section{b. Koefisien Gini}

Dalam suatu negara dapat diperoleh dengan menghitung luas daerah antara garis diagonal (kemerataan sempurna) dengan kurva Lorenz dibandingkan dengan luas total dari separuh bujur sangkar dimana kurva Lorenz itu berada.

Secara matematis rumus koefisien gini dapat disajikan sebgai berikut (Arsyad, 2010):

$\mathrm{KG}=1-\sum_{i=1}^{n}\left(X_{i+1}-X_{i}\right)\left(\mathrm{Y}_{i}+Y_{i+1}\right)$

Atau

$\mathrm{KG}=1-\sum_{i=1}^{n} f_{i}\left(Y_{i+1}+Y_{i}\right)$

Keterangan:

$\mathrm{KG}=$ angka Koefisien Gini

$\mathrm{Xi}=$ proporsi jumlah rumah tangga kumulatif dalam kelas ke i

fi $=$ proporsi jumlah rumah tangga dalam kelas ke i

$\mathrm{Yi}=$ proporsi jumlah pendapatan rumah rangga kumulatif dalam kelas ke $\mathrm{i}$

Koefisien Gini ini merupakan ukuran ketidakmerataan agregat dan nilainya terletak antara 0 (kemerataan sempurn) sampai 1 (ketidakmerataan sempurna). Semakin besar nilai indeks Gini, maka distribusi pendapatan semakin timpang dan semakin kecil indeks gini maka pendapatan semakin merata. Kategori ketimpangan pendapatan rumah tangga dapat diklasifikasikan sebagai berikut (Arsyad, 2010):

a. Ketimpangan rendah jika nilai indeks Gini berkisar antara 0,2-0,35 b. Ketimpangan sedang antara 0,360,49

c. Ketimpangan tinggi berkisar antara $0,5-0,7$

Bank Dunia mengkategorikan ketimpangan tinggi jika $40 \%$ penduduk berpendapatan rendah menerima kurang dari $12 \%$ pendapaatn total, ketimpangan sedang menerima $12-17 \%$ dari pendapatan total, dan ketimpangan tinggi jika menerima lebih dari $17 \%$ dari pendapatan total.

\section{METODE PENELITIAN}

\section{Jenis dan Sumber Data}

Data yang digunakan dalam penelitian ini merupakan sebagian data yang diambil dari data hibah komprehensif tahun 2013 yang berjudul "Perubahan Iklim dan Dampaknya terhadap Kinerja dan Risiko Usahatani Tebu di wilayah Kerja PG Madukismo" yang diteliti oleh Dr.Ir Slamet Hartono, SU, M.Sc. Dalam penelitian ini peneliti bertindak sebagai asisten penelitian. Daerah yang dijadikan sebagai lokasi penelitian adalah Kabupaten Bantul. Pemilihan lokasi penelitian dilakukan secara sengaja (purposive), hal ini dikarenakan Kabupaten Bantul merupakan salah satu kabupaten yang menjadi mitra PG Madukismo. Penelitian dilakukan hanya di 7 kecamatan, yaitu Piyungan, Sewon, Sedayu, Kasihan, Jetis, Pajangan dan Imogiri. Hal ini dikarenakan petani tebu mitra PG Madukismo hanya berada di 7 kecamatan tersebut.

Pengambilan sampel dilakukan secara sengaja (purposive), yaitu pengambilan sampel berdasarkan kesengajaan, pemilihan sekelompok subyek didasarkan atas ciri atau sifat tertentu yang dipandang mempunyai sangkut-paut yang erat dengan ciri atau sifat populasi yang sudah diketahui sebelumnya (Soekartawi, 2006). Petani sampel merupakan petani tebu yang mengusahakan tebu tanam yang menjadi mitra PG Madukismo. Jumlah petani tebu yang menjadi sampel dalam penelitian sebanyak 30 orang petani tebu. 


\section{Metode Analisis Data}

Untuk mengetahui produksi tebu dan faktor-faktor yang mempengaruhinya, menggunakan model regresi sebagai berikut:

$$
\begin{aligned}
\operatorname{Ln} \text { Prod }= & \operatorname{Ln} \alpha_{0}+\alpha_{1} \ln \mathrm{LL}+\alpha_{2} \ln \mathrm{BBT}+\alpha_{3} \ln \\
& \mathrm{PHS}+\alpha_{4} \ln \mathrm{ZA}+\alpha_{5} \ln \mathrm{PTR}+\alpha_{6} \ln \\
& \mathrm{PST}+\alpha_{7} \ln \mathrm{TKG}+\alpha_{8} \ln \mathrm{TKP}+ \\
& \mathrm{d} 1 \mathrm{D} 1+\varepsilon
\end{aligned}
$$

Keterangan:

PROD : produksi per ha (ku/ha)

LL : luas lahan (ha)

BBT : penggunaan bibit per ha $(\mathrm{ku} / \mathrm{ha})$

PHS : penggunaan pupuk Phonska per ha (ku/ha)

ZA : penggunaan pupuk ZA per ha $(\mathrm{ku} / \mathrm{ha})$

PTR : penggunaan pupuk Petroganik per ha (ku/ha)

PST : penggunaan pestisida per ha ( $1 / \mathrm{ha})$

TKG : penggunaan tenaga kerja per ha (HKO/ha)

TKP : penggunaan tenaga kerja panen (HKO/ha)

D : Dummy sistem penanaman tebu

Analisis faktor-faktor yang mepengaruhi pendapatan usahatani tebu menggunakan model regresi:

$$
\begin{aligned}
\ln \text { Pdpt* }^{*}= & \text { Ln } \alpha_{0}+\alpha_{1} \ln \text { Lhn }+\alpha_{2} \ln \text { HBbt* }^{*}+\alpha_{3} \\
& \ln \text { HPhs }^{*}+\alpha_{4} \ln \text { HZA }^{*}+\alpha_{5} \ln \\
& \text { HPtrg* }+\alpha_{6} \ln \text { Hpest* }+\alpha_{7} \ln \text { HTkg }^{*} \\
& +\alpha_{8} \ln \text { HTkp }^{*}+\text { d1D } 1+\varepsilon
\end{aligned}
$$

Keterangan:

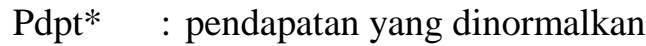

Lhn : luas lahan (ha)

HBbh* : harga benih yang dinormalkan

HPhn* : harga Phonska yang dinormalkan

HZA* : harga ZA yang dinormalkan

HPtrg* : harga Petroganik yang dinormalkan

Hpest* : harga pestisida yang dinormalkan

HTkg* : upah tenaga kerja garap yang dinormalkan

HTkp* : upah tenaga kerja panen yang dinormalkan

D : sistem usahatani tebu

Untuk mengetahui risiko produksi dan risiko pendapatan tebu, digunakan cara:

$$
\mathrm{CVP}=\frac{\sigma_{Q}}{Q}
$$

Keterangan :

CVP : koefisien variansi produksi tebu

$\sigma_{\mathrm{Q}}$ : standar deviasi produksi per hektar $(\mathrm{Ku} / \mathrm{ha})$

Q : rata-rata produksi per hektar $(\mathrm{Ku})$

$$
\mathrm{CVR}=\frac{\sigma_{R}}{R}
$$

Keterangan :

CVR : koefisien variansi pendapatan tebu

$\sigma_{\mathrm{R}}$ : standar deviasi pendapatan per hektar (Rp/ha)

$\mathrm{R} \quad$ : rata-rata pendapatan per hektar $(\mathrm{Rp})$

Untuk mengetahui kontribusi pendapatan tebu terhadap pendapatan total rumah tangga tani. Dilakukan pengujian menggunakan rumus:

$$
\mathrm{X}=\frac{p_{1}}{p_{t}} \times 100 \%
$$

Keterangan:

$\mathrm{X}$ : persentase sumbangan pendapatan usahatani tebu terhadap pendapatan total rumah tangga tani

P1 : pendapatan usahatani tebu $(\mathrm{Rp})$

$\mathrm{Pt}$ : pendapatan total rumah tangga tani (Rp)

Suratiyah dan Hariyadi (1990), menentukan besarnya kontribusi pendapatan terhadap pendapatan total digunakan kriteria sebgai berikut:

a. Jika kontribusi pendapatan $<25 \%$, kontribusinya kecil

b. Jika kontribudi pendapatan 25-49\%, kontribusinya sedang

c. Jika kontribusi pendapatan 50-75\%, kontribusi besar

d. Jika kontribusi pendapatan > $75 \%$, kontribusi besar sekali

Untuk mengetahui distribusi pendapatan petani tebu di Kabupaten Bantul, dilakukan pengujian dengan menggunakan indeks Gini. Model analisis Indeks Gini (Mahyudi, 2004) adalah:

$$
\mathrm{GR}=1-\sum_{i=1}^{k} \frac{Y_{j}+Y_{j-1}}{k}
$$


Keterangan:

$Y_{j}$ : persentase kumulatif yang diterima sampai kelompok ke-j

$\mathrm{Y}_{\mathrm{j}-1}$ : persentase kumulatif pendapatan yang diterima sampai kelompok sebelumnya

$\mathrm{K}$ : jumlah kelompok(kelas)

Untuk menentukan apakah distribusi pendapatan petani tebu merata atau timpang digunakan kriteria sebagai berikut:

a. Ketimpangan rendah jika nilai indeks Gini berkisar antara 0,2-0,35

b. Ketimpangan sedang antara $0,36-0,49$

c. Ketimpangan tinggi berkisar antara $\geq 0,5$.

Untuk mengetahui tingkat kesejahteraan petani tebu di Kabupetan Bantul. Digunakan metode Pangsa Pengeluaran pangan (PPP) dan Good Servise Ratio (GSR). Pangsa Pengeluaran Pangan (PPP) rumah tangga tani menggunakan persamaan sebagai berikut:

$$
\mathrm{PPP}=\frac{F E}{T E} \times 100 \%
$$

\section{Dimana:}

PPP : Pangsa Pengeluaran Pangan (\%)

FE : Pengeluaran untuk belanja kebutuhan pangan (Rp/tahun)

TE : Total Pengeluaran Kebutuhan Rumah Tangga (Rp/tahun)

Hasil dari perhitungan tersebut tentunya akan dihasilkan persentase yang dapat dikategorisasikan dengan ketentuan:

- Kategori Pengeluaran Pangan Rendah, yaitu apabila PPP < 60\% dari Pengeluaran Total

- Kategori Pengeluaran Pangan Tinggi, yaitu apabila PPP $\geq 60 \%$ dari Pengeluaran Total

Untuk mengetahui tingkat kesejahteraan rumah tangga diukur dengan menggunakan Good Servise Ratio (GSR) dengan rumus:

GSR $=\frac{\text { Pengeluaran untuk kebutuhan pangan }}{\text { pengeluaran unutk kebutuhan non pangan }}$

Keterangan:

GSR > 1 artinya ekonomi rumah tangga kurang sejahtera

GSR = 1 artinya ekonomi rumah tangga sejahtera

GSR $<1$ artinya ekonomi rumah tangga lebih sejahtera
HASIL DAN PEMBAHASAN

Produksi Tebu dan Faktor-faktor yang Mempengaruhinya

\section{Koefisien Determinasi}

Hasil analisis regresi menunjukkan nilai koefisien determinasi (Adjusted $R^{2}$ ) adalah 0,943. Hal ini menunjukkan 94,3\% variabel dependen dapat dijelaskan terhadap variabel independen. Sisanya $5,7 \%$ dijelaskan oleh variabel yang lain di luar model.

\section{Uji F}

Berdasarkan hasil analisis nilai $\mathrm{F}$ hitung sebesar 135,604. Pada tingkat kepercayaan 95\% nilai $F$ tabel sebesar 2,006. Nilai f hitung lebih besar dari $F$ tabel $(135,604>2,006)$ yang berarti bahwa secara bersama-sama variabel independen berpengaruh terhadap variabel dependen.

\section{Uji t}

Uji t untuk mengetahui apakah masingmasing variabel independen berpengaruh secara signifikan terhadap variabel dependen. Berdasarkan hasil analisis pada tabel faktorfaktor yang mempengaruhi produksi tebu di Kabupaten Bantul adalah luas lahan, jumlah bibit, jumlah pupuk ZA, jumlah pestisida, jumlah tenaga kerja garab, jumlah tenaga kerja panen dan sistem penanaman tebu.

\section{Pendapatan Tebu dan Faktor-faktor yang Mempengaruhinya}

\section{Koefisien Determinasi}

Hasil analisis regresi menunjukkan nilai koefisien determinasi (Adjusted $R^{2}$ ) adalah 0,813. Hal ini menunjukkan 81,3\% variabel dependen dapat dijelaskan terhadap variabel independen. Sisanya $19,7 \%$ dijelaskan oleh variabel yang lain di luar model.

\section{Uji F}

Berdasarkan hasil analisis nilai $\mathrm{F}$ hitung sebesar 36,63. Pada tingkat kepercayaan 95\% nilai $F$ tabel sebesar 2,464. Nilai $F$ hitung lebih besar dari $\mathrm{F}$ tabel $(36,63>2,464)$ yang berarti bahwa secara bersama-sama variabel independen berpengaruh terhadap variabel dependen.

\section{Uji t}

Uji t untuk mengetahui apakah masingmasing variabel independen berpengaruh secara signifikan terhadap variabel dependen. Berdasarkan tabel yang menjyajikan hasil analisis 
Tabel 1. Hasil Uji Regresi Faktor Produksi Tebu di Kabupaten Bantul, 2012

\begin{tabular}{|c|c|c|c|}
\hline Expected sign & Koefisien Regresi & t Hitung & Sig. \\
\hline Konstanta & $4,153 \quad * * *$ & 16,954 & 0,000 \\
\hline Luas Lahan & 0,292 & 6,086 & 0,000 \\
\hline Bibit & 0,159 & 4,353 & 0,000 \\
\hline Phonska & 0,043 & 1,117 & 0,268 \\
\hline $\mathrm{ZA}$ & 0,131 & 2,569 & 0,012 \\
\hline Petroganik & $-0,081$ & $-1,566$ & 0,122 \\
\hline Pestisida & 0,122 & 1,804 & 0,075 \\
\hline TKG & 0,126 & 2,586 & 0,012 \\
\hline TKP & 0,245 & 4,003 & 0,000 \\
\hline D1 & $-0,250$ & $-2,949$ & 0,004 \\
\hline $\mathrm{D} 2$ & $0,118 *$ & 1,791 & 0,078 \\
\hline \multicolumn{3}{|l|}{ Adjusted R2 } & 0,943 \\
\hline \multicolumn{3}{|l|}{ F Hitung } & $135,604 * * *$ \\
\hline
\end{tabular}

Sumber: Analisis Data Primer, 2013

Keterangan:

$* * *=$ signifikansi pada tingkat kepercayaan $99 \%(\alpha=0,01 ; \mathrm{n}=30 ; \mathrm{t}$ tabel $=2,749)$

$* *$ = signifikansi pada tingkat kepercayaan $95 \%(\alpha=0,05 ; \mathrm{n}=30 ; \mathrm{t}$ tabel $=2,042)$

$*=$ signifikansi pada tingkat kepercayaan $90 \%(\alpha=0,1 ; \mathrm{n}=30 ; \mathrm{t}$ tabel $=1,697)$

ns= tidak signifikan

Tabel 2. Hasil Uji Regresi Faktor Data Pendapatan di Kabupaten Bantul, 2012

\begin{tabular}{|c|c|c|c|}
\hline Expected Sign & Koefisien Regresi & t Hitung & Sig. \\
\hline Konstanta & $-0,202 \mathrm{~ns}$ & $-0,069$ & 0,945 \\
\hline $\mathrm{LL}$ & 0,756 & 14,878 & 0,000 \\
\hline HBBT & $-0,398$ & $-1,893$ & 0,062 \\
\hline HPHS & $-0,693$ & $-0,728$ & 0,469 \\
\hline HZA & 1,199 & 1,110 & 0,271 \\
\hline HPTR & $-0,762$ & $-0,524$ & 0,602 \\
\hline HPST & 0,565 & 1,141 & 0,258 \\
\hline HTKG & $-0,471$ & $-1,909$ & 0,060 \\
\hline HTKP & $-0,290$ & $-1,429$ & 0,157 \\
\hline D1 & $-0,188$ & $-1,755$ & 0,084 \\
\hline $\mathrm{D} 2$ & 0,175 & 1,685 & 0,096 \\
\hline \multicolumn{3}{|l|}{ Adjusted $R^{2}$} & 0,813 \\
\hline F Hitung & & & $36,63 * * *$ \\
\hline
\end{tabular}

Sumber: Analisis Data Primer, 2013

fungsi pendapatan maka dapat diketahui bahwa luas lahan, harga pupuk phonska dan sisitem penanaman tebu memiliki pengaruh yang signifikan terhadapa pendapatan petani tebu.

\section{Risiko Produksi dan Risiko Pendapatan Tebu Tanam dan Tebu Keprasan}

Penilaian risiko produksi dan risiko pendapatan usahatani tebu didasarkan pada jenis petani dalam menanam tebu, yaitu petani tebu tanam, tebu keprasan 1 dan tebu keprasan 2. Untuk mengetahui risiko produksi dilakukan analisis koefisien variansi (CV), yaitu perbandingan antara nilai standar deviasi dengan nilai rata-rata produksi. Semakin kecil nilai koefisien variansi (CV) maka akan semakin rendah risiko yang dihadapi. Hasil analisis koefisien variansi produksi petani tebu di Kabupaten Bantul dapat dilihat pada tabel 3.

Berdasarkan tabel 3, menunjukkan bahwa nilai koefisien variansi produksi secara berurutan dari yang paling tinggi adalah tebu keprasan2, tebu tanam dan tebu keprasan 1. 
Tabel 3. Risiko Produksi Usahatani Tebu di Kabupaten Bantul, 2012

\begin{tabular}{|l|r|r|r|}
\hline \multicolumn{1}{|c|}{ Uraian } & Petani Tebu Tanam & Petani Tebu Keprasan 1 & Petani Tebu Keprasan 2 \\
\hline Produktivitas (Ku/ha) & 784,792 & 792,152 & 752,525 \\
\hline Standar Deviasi & 111,103 & 109,120 & 113,957 \\
\hline Koefisien Variansi & 0,142 & 0,138 & 0,151 \\
\hline
\end{tabular}

Sumber: Analisis Data Primer, 2013

Tabel 4. Risiko Pendapatan Usahatani Tebu di Kabupaten Bantul, 2012

\begin{tabular}{|l|r|r|r|}
\hline \multicolumn{1}{|c|}{ Uraian } & Petani Tebu Tanam & Petani Tebu Keprasan 1 & Petani Tebu Keprasan 2 \\
\hline Pendapatan Per Ha (Rp) & 23.119 .051 & 29.452 .140 & 22.344 .645 \\
\hline Standar Deviasi & $60.805,076$ & $63.244,471$ & $83.919,053$ \\
\hline Koefisien Variansi & 2,630 & 2,147 & 3,756 \\
\hline
\end{tabular}

Sumber: Analisis Data Primer, 2013

Hal ini menunjukkan tebu keprasan 2 memiliki risiko produksi paling tinggi. Berdasarkan tabel menunjukkan bahwa nilai koefisien variansi pendapatan secara berurutan dari yang paling tinggi adalah tebu keprasan2, tebu tanam dan tebu keprasan 1. Hal ini menunjukkan tebu keprasan 2 memiliki risiko pendapatan paling tinggi.

\section{Kontribusi Pendapatan Tebu Tanam dan Tebu Keprasan}

Pendapatan rumah tangga tani dalam penelitian ini merupakan hasil penjumlahan dari pendapatan usahatani tebu, pendapatan bukan usahatani tebu, dan pendapatan luar usahatani. Keberagaman sumber pendapatan yang dimiliki oleh rumah tangga petani memiliki nilai kontribusi masing-masing pada total pendapatan rumah tangga petani. Gambaran masing-masing sumber pendapatan dan kontribusinya pada pendapatn rumah tangga tani di Kabupaten Bantul dapat dilihat pada tabel 5.
Berdasarkan tabel kontribusi yang paling tinggi terhadap pendapatan total rumah tangga adalah pendapatan dari tebu baik tebu tanam, tebu keprasan 1 maupun keprasan 2. Kontribusi pendapatan tebu untuk tebu tanam, tebu keprasan 1 dan tebu keprasan 2 terhadap pendapatan total menunjukkan nilai lebih besar dari $75 \%$, yaitu $82 \%, \quad 87 \%$ dan $81 \%$. Nilai kontribusi menunjukkan nilai yang sangat tinggi. Hal ini menunjukkan bahwa sebagian besar petani tebu di Kabupaten Bantul sumber utama penghasilan rumah tangganya adalah usahatani tebu.

\section{Distribusi Pendapatan Petani Tebu}

\section{Indeks Gini}

Cara pengukuran distribusi pendapatan dengan Indeks Gini berupa angka yang besarnya terletak antara nol dan satu. Semakin mendekati nol berarti semakin baik distribusinya, sebaliknya semakin mendekati angka satu distribusi pendapatan semakin buruk atau timpang. Indeks Gini untuk masing-masing pendapatan dapat

Tabel 5. Tabel Kontribusi Pendapatan terhadap Pendapatan Total Rumah Tangga Petani Tebu di Kabupaten Bantul, 2012

\begin{tabular}{|l|r|r|r|r|r|r|}
\hline \multicolumn{1}{|c|}{ Uraian } & Tebu Tanam & Kontribusi & $\begin{array}{r}\text { Tebu Keprasan } \\
1\end{array}$ & Kontribusi & $\begin{array}{c}\text { Tebu } \\
\text { Keprasan 2 }\end{array}$ & Kontribusi \\
\hline $\begin{array}{l}\text { Pendapatan } \\
\text { Tebu }\end{array}$ & $69,638,985$ & $82 \%$ & $109,476,956$ & $87 \%$ & $71,277,442$ & $81 \%$ \\
\hline $\begin{array}{l}\text { Pendapatan } \\
\text { Tanaman Lain }\end{array}$ & $5,947,273$ & $7 \%$ & $3,835,900$ & $3 \%$ & $4,399,842$ & $5 \%$ \\
\hline $\begin{array}{l}\text { Pendapatan } \\
\text { Luar Usahatani }\end{array}$ & $9,818,182$ & $11 \%$ & $12,786,332$ & $10 \%$ & $12,319,558$ & $14 \%$ \\
\hline $\begin{array}{l}\text { Pendapatan } \\
\text { Total }\end{array}$ & $85,404,440$ & & $126,099,187$ & & $87,996,842$ & \\
\hline
\end{tabular}

Sumber: Analisis Data Primer, 2013 
dilihat pada tabel 6,7,8.

Berdasarkan tabel 6, terlihat bahwa dengan adanya pendapatan dari usahatani tebu tanam, nilai ketimpangan pendapatan total rumah tangga tebu tanam menjadi lebih kecil, artinya distribusi pendapatan menjadi semakin rata. dibandingkan dengan pendapatan tanpa tebu tanam. Secara garis besar dapat diketahui bahwa dengan adanya pendapatan dari tebu tanam, pendapatan total rumah tangga antar petani tebu tanam menjadi lebih merata.

Berdasarkan Kurva Lorenz menunjukkan

Tabel 6. Tabel Indeks Gini antara Pendapatan Non Tebu Tanam dan Pendapatan Total Rumah Tangga Tani Tebu Tanam di Kabupaten Bantul, 2012

\begin{tabular}{|l|c|}
\hline \multicolumn{1}{|c|}{ Uraian } & Indeks Gini \\
\hline Pendapatan Tanpa Tebu Tanam & 0,482 \\
\hline Pendapatan Total Rumah Tangga Petani Tebu Tanam & 0,312 \\
\hline
\end{tabular}

Sumber: Analisis Data Primer, 2013

Tabel 7. Tabel Indeks Gini antara Pendapatan Non Tebu Keprasan 1 dan Pendapatan Total Rumah Tangga Tani Tebu Keprasan 1 di Kabupaten Bantul, 2012

\begin{tabular}{|l|c|}
\hline \multicolumn{1}{|c|}{ Uraian } & Indeks Gini \\
\hline Pendapatan Tanpa Tebu Keprasan 1 & 0,813 \\
\hline Pendapatan Total Rumah Tangga Petani Tebu keprasan 1 & 0,286 \\
\hline
\end{tabular}

Sumber: Analisis Data Primer, 2013

Tabel 8. Tabel Indeks Gini antara Pendapatan Non Tebu Keprasan 2 dan Pendapatan Total Rumah Tangga Tani Tebu Keprasan 2 di Kabupaten Bantul, 2012

\begin{tabular}{|l|c|}
\hline \multicolumn{1}{|c|}{ Uraian } & Indeks Gini \\
\hline Pendapatan Tanpa Tebu Keprasan 2 & 0,606 \\
\hline Pendapatan Total Rumah Tangga Petani Tebu keprasan 2 & 0,312 \\
\hline
\end{tabular}

Sumber: Analisis Data Primer, 2013

Berdasarkan tabel 7. terlihat bahwa dengan adanya pendapatan dari usahatani tebu keprasan 1 , nilai ketimpangan pendapatan total rumah tangga tebu keprasan 1 menjadi lebih kecil, artinya distribusi pendapatan menjadi semakin rata.

Berdasarkan tabel 8. terlihat bahwa dengan adanya pendapatan dari usahatani tebu keprasan 2, nilai ketimpangan pendapatan total rumah tangga tebu keprasan 2 menjadi lebih kecil, artinya distribusi pendapatan menjadi semakin rata.

\section{Kurva Lorenz}

Semakin cembung kurva yang terbentuk dari garis keseimbangan $\left(45^{\circ}\right)$ maka semakin tidak merata distribusi pendapatan petani tebu baik tebu tanam maupun tebu keprasan. Apabila kurva Lorenz yang terbentuk berada di dekat garis keseimbangan maka dapat diartikan bahwa distribusi pendapatan petani lebih merata.

$$
\text { Berdasarkan Kurva Lorenz 1-3 }
$$
menunjukkan bahwa pendapatan total rumah tangga petani tebu tanam lebih merata bahwa pendapatan total rumah tangga petani tebu keprasan 1 lebih merata dibandingkan dengan pendapatan tanpa tebu keprasan 1. Secara garis besar dapat diketahui bahwa dengan adanya pendapatan dari tebu keprasan 1, pendapatan total rumah tangga antar petani tebu keprasan 1 menjadi lebih merata.

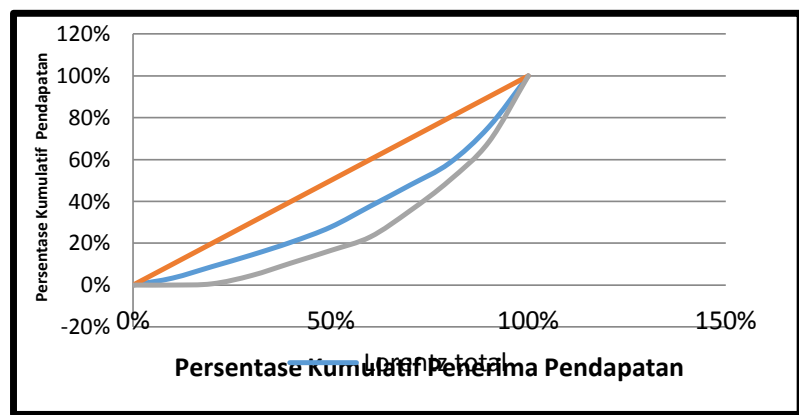

Kurva 1. Kurva Lorenz Pendapatan Non Tebu Tanam dan Pendapatan Total Rumah Tangga Tani Tebu Tanam di Kabupaten Bantul, 2012

Sumber: Analisis Data Primer, 2013

Berdasarkan Kurva Lorenz tersebut menunjukkan bahwa pendapatan total rumah tangga petani tebu keprasan 2 lebih merata dibandingkan dengan pendapatan tanpa tebu 
keprasan 2. Secara garis besar dapat diketahui bahwa dengan adanya pendapatan dari tebu keprasan 2, pendapatan total rumah tangga antar petani tebu keprasan 2 menjadi lebih merata.

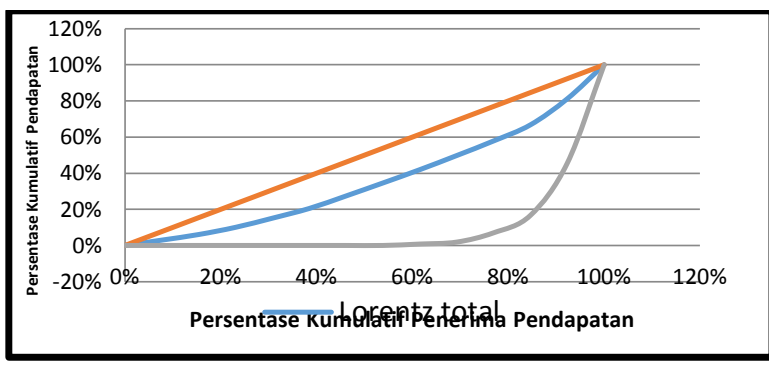

Kurva 2. Kurva Lorenz Pendapatan Non Tebu Keprasan 1 dan Pendapatan Total Rumah Tangga Tani Tebu Keprasan 1 di Kabupaten Bantul, 2012

Sumber: Analisis Data Primer, 2013

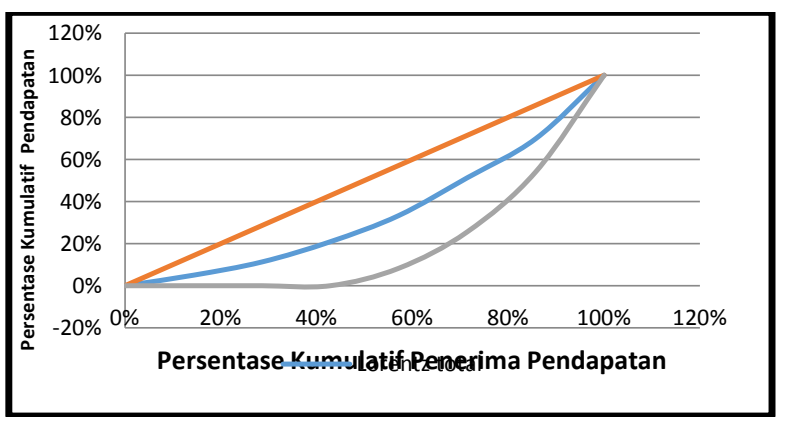

Kurva 3. Kurva Lorenz Pendapatan Non Tebu Keprasan 2 dan Pendapatan Total Rumah Tangga Tani Tebu Keprasan 2 di Kabupaten Bantul, 2012

Sumber: Analisis Data Primer, 2013

\section{Analisis Kesejahteraan Rumah Tangga Tani}

Analisis kesejahteraan dilakukan untuk mengetahui keadaan ekonomi rumah tangga petani. Dalam ekonomi rumah tangga, perhitungan pendapatan dan pengeluaran rumah tangga dapat digunakan untuk mencerminkan tingkat kesejahteraan. Dalam penelitian ini untuk mengetahui tingkat kesejahteraan rumah tangga tani dilakukan dengan membandingkan pengeluaran pangan dengan pengeluaran non pangan atau biasa disebut dengan metode Good Servise Ratio (GSR). Jika nilai GSR lebih dari 1 maka rumah tangga tani dianggap kurang sejahtera. Nilai GSR yang menunjukkan sama dengan 1 maka rumah tangga tani dianggap sejahtera. Nilai GSR menunjukkan nilai kurang dari 1 maka rumah tangga tani dianggap lebih sejahtera. Nilai GSR dapat dilihat pada tabel 9 berikut.

Tabel 9. Hasil Uji Good Servise Ratio (GSR) Petani tebu di Kabupaten Bantul, 2012

\begin{tabular}{|c|r|r|}
\hline & \multicolumn{1}{|c|}{ Jumlah } & \multicolumn{1}{|c|}{ Persentase } \\
\hline GSR $>1$ & 1 & $3 \%$ \\
\hline GSR $=1$ & 0 & $0 \%$ \\
\hline GSR $<1$ & 29 & $97 \%$ \\
\hline Jumlah & 30 & $100 \%$ \\
\hline
\end{tabular}

Sumber: Analisis data Primer, 2013

Berdasarkan tabel 9 terlihat bahwa persentase GSR < 1 lebih besar yaitu 97\%, sehingga dapat disimpulkan bahwa sebanyak 97\% petani tebu di Kabupaten Banttul adalah rumah tangga yang lebih sejahtera.

\section{KESIMPULAN DAN SARAN}

\section{Kesimpulan}

1. Faktor-faktor yang berpengaruh secara positif terhadap produksi usahatani tebu di Kabupaten Bantul adalah luas lahan, jumlah bibit, jumlah pupuk ZA, jumlah pestisida, jumlah tenaga kerja garap dan jumlah tenaga kerja panen.

2. Pendapatan tebu per hektar untuk tebu keprasan 1 lebih tinggi daripada pendapatan tebu tanam dan keprasan 2 per hektar.

3. Faktor-faktor yang berpengaruh secara positif terhadap pendapatan usahatani tebu di Kabupaten bantul adalah luas lahan, sedangkan faktor yang berpengaruh secara negatif terhadap pendapatan adalah harga bibit yang dinormalkan dan upah tenaga kerja garap yang dinormalkan.

4. Risiko usahatani tebu dari yang paling rendah risikonya baik risiko produksi maupun risiko pendapatan adalah tebu keprasan 1, tebu tanam dan tebu keprasan 2.

5. Kontribusi pedapatan usahatani tebu baik tebu tanam, keprasan 1 dan keprasan 2 hampir sama yaitu memiliki kontribusi yang tinggi terhadap pendapatan total.

6. Pendapatan usahatani tebu baik tebu tanam, tebu keprasan 1 dan tebu keprasan 2 memperkecil ketimpangan pendapatan total rumah tangga.

7. Rumah tangga tani tebu merupakan rumah tangga yang sejahtera. 


\section{Saran}

Upaya untuk meningkatkan produksi tebu di Kabupaten Bantul dapat dilakukan dengan cara intensifikasi pertanian yaitu meliputi penambahan kualitas dan kuantitas penggunaan bibit, ZA dan pestisida. Hal ini dikarenakan di Kabupaten Bantul sudah tidak memungkinkan lagi untuk upaya perluasan lahan untuk usahatani tebu. Sistem penanaman tebu sebaiknya sampai keprasan 1 setelah itu diharapkan petani melakukan sistem tebu tanam, karena produktivitas pada tebu keprasan 2 lebih rendah daripada tanam.

\section{DAFTAR PUSTAKA}

Arsayd, Licolin. 2010. Ekonomi Pembangunan Edisi Kelima. Yogyakarta: STIE YKPN

Booker Tate Ltd. 1999. Study of The Indonesian Sugar Industry, (vol 1-3). Research Report for Meneg BUMN, UK. Jakarta.

Gilarso, T. 1992. Pengantar Ilmu Ekonomi Bagian Makro. Kanisius. Yogyakarta

Gujarati, Damodar N. 2006. Dasar-dasar Ekonometrika. Penerbit Erlangga, Jakarta

Haryanto, T., Hidayati, N.A dan Wagiono Djoewito. 2009. Ekonomi Pertanian. Airlangga University Press, Surabaya.

Lembaga Penelitian IPB. 2002. Studi Pengembangan Sistem Industri Pergulaan Nasional. Kerjasama antara Ditjen Bina Perkebunan dengan LP IPB, Bogor, Desember 2002

Mahyudi, A. 2004. Ekonomi Pembangunan dan Analisis Data Empiris. Ghalia Indonesia, Bogor.

Mubyarto. 1997. Pengantar Ekonomi Pertanian Edisi Ketiga. LP3ES. Jakarta

Muslim, A. 2002. Program Swasembada dan Kebijakan Gula di Indonesia, LPFE: Lembaga Penerbit FE Universitas Trisakti. Jakarta. Hal 277-299

Pusat Penelitian dan Pengembangan Gula Indonesia (p3GI). 2003. Studi Konsolidasi Pergulaan Nasional. Kerjasama Ditjen BPP Deptan dengan P3GI, Jakarta

Soedarsono H., 1975. Biaya dan Pendapatan di Dalam Usahatani. Departemen Ekonomi Pertanian. Fakultas Pertanian Universitas Gadjah Mada, Yogyakarta
Soekartawi. 1994. Teori Ekonomi Produksi: Pokok Bahasan analisis fungsi produksi cobb douglas. Raja grafindo persada, jakarta.

Soekartawi. 1995. Analisis usahatani. UI- Press. Jakarta

Suratiyah, K., S.S. Hariadi. 1991. Wanita, Kerja dan Rumah Tangga: Pengaruh Pembangunan Pertanian Terhadap Peranan Wanita Pedesaan di Daerah Istimewa Yogyakarta. Pusat Penelitian Kependudukan UGM, Yogyakarta

Teken, I.B. 1965. Penelitian di Bidang Ilmu Ekonomi Pertanian dan Beberapa Metode Pengambilan Contoh. Fakultas Pertanian IPB. Bogor

Wijaya, Tony. 2009. Analisis Data Penelitian Menggunakan SPSS. Penerbit Universitas Atma Jaya, Yogyakarta.

World Bank, 2006. Era Baru Pengentasan Kemiskinan di Indonesia. Gradasi Aksara.Jakarta.

Yotopoulus, P and J. Nugent. 1976. Economic of Development. New York, Harper Row Publisher. 